\title{
Computation of X-ray powder diffractograms of cement components and its application to phase analysis and hydration performance of OPC cement
}

\author{
ROHAN JADHAV and N C DEBNATH* \\ Department of Physics, Institute of Chemical Technology, Mumbai 400 019, India
}

MS received 14 October 2010; revised 2 February 2011

\begin{abstract}
The importance of computed X-ray diffraction patterns of various polymorphs of alite $\left(M_{3}, T_{1}, R\right)$, belite $(\beta, \gamma)$, aluminate (cubic, orthorhombic), aluminoferrite, gypsum and hemihydrate in the quantitative phase analysis of cement and its early stage hydration performance is highlighted in this work with three OPC samples. The analysis shows that the predominant silicate phases present in all the samples are $M_{3}$-alite phase and $\beta$-belite phase, respectively. Both cubic and orthorhombic phases of $\mathrm{C}_{3} \mathrm{~A}$, brownmillerite, gypsum and hemihydrates are present at different levels. Quantitative phase analysis of cement by Rietveld refinement method provides more accurate and comprehensive data of the phase composition compared to Bogue method. The comparative hydration performance of these samples was studied with $w / c$ ratio, 0.5 and the results are interpreted in the light of difference in phase compositions viz. $\beta-C_{2} S / C_{3} S$ ratio, fraction of finer cement particles present in the samples and theoretical modeling of $\mathrm{C}_{3} \mathrm{~S}$ hydration.
\end{abstract}

Keywords. Portland cement; X-ray diffraction; crystal structure; characterization; Rietveld method.

\section{Introduction}

Ordinary Portland cement and clinker are highly complex materials consisting of several crystalline phases. The four major components of OPC cement are alite $\left(\mathrm{C}_{3} \mathrm{~S}-\mathrm{Ca}_{3} \mathrm{SiO}_{5}\right)$, belite $\left(\mathrm{C}_{2} \mathrm{~S}-\mathrm{Ca}_{2} \mathrm{SiO}_{4}\right)$, aluminate $\left(\mathrm{C}_{3} \mathrm{~A}-\mathrm{Ca}_{3} \mathrm{Al}_{2} \mathrm{O}_{6}\right)$, and aluminoferrite $\left(\mathrm{C}_{4} \mathrm{AF}\right)$ while, the minor components are gypsum, calcium sulphate hemihydrate etc. Each of the major components, in turn, can exist in several polymorphic phases. Alite has seven polymorphic forms, belite can be in four polymorphic forms, aluminate exists in two crystal forms, aluminoferrite exists in orthorhombic phase and calcium sulphates can have more than one crystal phases (Hewlett 1988; Taylor 1997). A comprehensive analysis of commercial cement requires the identification of the specific mineralogical phases of all major and minor components that are present in cement and also their relative abundance. Since the hydraulic properties of cement depend quite substantially on the specific mineralogical phase and its relative abundance in cement, both qualitative and quantitative phase analyses of different mineralogical phases of the components of cement are very important to understand and predict the performance of cement and the resulting concrete.

There are several methods which may be used to determine the phase and phase composition of the cement. X-ray powder diffraction method is highly suitable for both qualitative and quantitative phase analyses of cement and clinker. The

*Author for correspondence (ndebnath5@rediffmail.com) elemental composition of cement is usually determined by $\mathrm{X}$-ray fluorescence method (XRF). In cement industry, the most common method that is used to estimate the mineralogical composition of cement clinker from elemental composition of cement is known as Bogue method (Bogue 1955; Hewlett 1988; American Standard ASTM C 150-94). This method is based on the assumption that each of the four major components (alite, belite, aluminate and ferrite) of cement clinker is a function of four oxide components viz. $\mathrm{CaO}$, $\mathrm{SiO}_{2}, \mathrm{Al}_{2} \mathrm{O}_{3}$ and $\mathrm{Fe}_{2} \mathrm{O}_{3}$. This method is used worldwide as a quality control method for OPC cements. One of the basic assumptions used in Bogue calculation is thermal equilibrium of the system at high temperature, which may not necessarily be correct and may be a source of error in quantitative analysis. Bogue method normally underestimates $\left(\mathrm{C}_{3} \mathrm{~S}+\right.$ $\mathrm{C}_{2} \mathrm{~S}$ ) content, overestimates the $\mathrm{C}_{3} \mathrm{~A}$ fraction and underestimates the $\mathrm{C}_{4} \mathrm{AF}$ content (De La Torre et al 2002). The second method, quantitative phase analysis (QPA) of cement, is based on the analysis of X-ray powder diffraction patterns of cement with Rietveld refinement method (Rietveld 1969; Young et al 1977; Hill and Howard 1987; Bish and Howard 1988; Young 1993; De La Torre et al 2001; Costa and Marchi 2003; Scrivener et al 2004; Taylor and Hinezak 2004). Although Rietveld method does not require any internal standard like rutile or corundum, it requires the crystal structure of all the component phases to be known in advance, as the process consists of the comparison of the experimentally measured and theoretically calculated diffraction patterns of each component phase present in the cementitious material. 
One of the major problems encountered in the qualitative and quantitative analysis of cement is that there are strong overlapping of major diffraction peaks of all the main phases of cement components in the angular range of $2 \theta$ values from $30^{\circ}$ to $35^{\circ}\left(\mathrm{Cu} \mathrm{K} \mathrm{K}_{\alpha 1}, \lambda=1.540560 \AA\right)$, making the identification of the individual components extremely difficult. Second major problem which adds to the complexity of the diffractograms of cement is that each individual component like alite, belite, aluminate, and aluminoferrite can crystallize in several polymorphic forms depending on their composition and this must be identified a priori before the analysis can be undertaken. In order to address this problem we have used theoretical techniques to generate a set of X-ray powder diffractograms of the important phases of each individual component of cement from the representative samples of stable polymorphic forms of these components and their crystal structure data. This method provides the unique diffraction pattern of each polymorphic form which might be used as a standard for comparison and also for analysis of the multiphase composite material like cement and cement clinker.

The primary objective of this work is to compute theoretically the X-ray powder diffraction patterns of different polymorphs of alite, belite, aluminate, aluminoferrite and other minor phases like gypsum, hemihydrate etc that are normally present in cement and utilize the computed profiles for both qualitative and quantitative phase analysis of different OPC cement samples and also for analysis of their hydration performance. From literature search, we have identified several stable polymorphs of the four major components and several minor phases of cement with slight variation in their chemical composition and crystal structure data and computed their diffraction patterns by using various unit cell parameters, space groups, fractional atomic positions, thermal parameters, site occupation numbers etc which are determined from the experimental X-ray diffraction study of single crystals of those compounds (Colville and Geller 1971; Mondal and Jeffery 1975; Nishi and Takéuchi 1975, 1984; Golovastikov et al 1975; Jost et al 1977; Okada and Ossaka 1980; Udagawa et al 1980; Benzou et al 1995; Mumme 1995; Schofield et al 1996; Peterson 2003; Inorganic Crystal Structure Database).

The computed diffraction profiles which are unique for each polymorph have been used to establish the identity of each component and its specific crystal phase in the multiphase cement system, since the various components present in cement diffract independently (Stutzman 1996). Secondly, the peaks that are free from overlap from other phases can also be identified and used for quantitative analysis of individual phase present in a mixture of cement and other components. Finally, we have used the Rietveld method to carry out quantitative phase analysis of all the samples and compare the results with the data calculated by Bogue method. The effect of the difference in phase compositions and particle size distributions of these samples in early stage of hydration performance is discussed in detail in the light of theoretical model for hydration of $\mathrm{C}_{3} \mathrm{~S}$ particles.

\section{Experimental}

Three commercial cement samples $S 1, S 2$ and $S 3$ from different Indian manufacturers were used in this work for a comparative study of phase composition and hydration performance. Rutile sample Tiona-595 (Millennium Chemicals, Australia) was used in this work as an internal standard for measuring the degree of hydration of these samples by QXRD technique (Taylor 1997). In order to study the progress of cement hydration, cement paste samples were prepared with water to cement ratio of 0.5 and the hydration reaction was monitored for $6 \mathrm{~h}, 12 \mathrm{~h}, 18 \mathrm{~h}, 24 \mathrm{~h}$ and 3 days and the corresponding samples were prepared by first dipping each paste sample in acetone for $30 \mathrm{~min}$ and subsequently dipping in diethyl ether for another $30 \mathrm{~min}$. The samples were then dried in an oven for $3 \mathrm{~h}$ at $105^{\circ} \mathrm{C}$ and ground to fine powder using mortar and pestle. The paste samples analysed by QXRD technique were prepared by homogeneously mixing dried cement paste powder and rutile in the weight ratio of $5: 1$ and the corresponding diffractograms were recorded for quantitative measurement of the degree of hydration $(\alpha)$. The progress of hydration reaction in cement paste was monitored by measuring the amount of unreacted $\mathrm{C}_{3} \mathrm{~S}$ component present in the paste as a function of hydration time.

The X-ray diffractograms of different samples were recorded on Panalytical X'Pert PRO X-ray diffractometer with Bragg-Brentano geometry. The wavelengths of X-rays used in this work for recording data were $\mathrm{Cu} \mathrm{K}_{\alpha}$ radiation, $\lambda_{1}=$ $1.540560 \AA$ and $\lambda_{2}=1.544390 \AA$ with $\lambda_{2} / \lambda_{1}=0.5$. Powder samples were loaded on aluminum sample holder having dimensions $2 \times 1.5 \times 0.2 \mathrm{~cm}$ (vol. $\left.0.6 \mathrm{~cm}^{3}\right)$. The experimental conditions for data recording were as follows: X-ray tube was operated at $40 \mathrm{kV}$ with $30 \mathrm{~mA}$, fixed divergence slit with slit size $1 \cdot 0^{\circ}$, step size of $0 \cdot 017^{\circ}$ with $5 \cdot 1686 \mathrm{~s} / \mathrm{step}$. The data was collected for each sample over $2 \theta$ values ranging from $4^{\circ}$ to $80^{\circ}$.

Similarly, XRF data of cement samples were generated on Philips PW2404 XRF spectrometer. The X-ray tube was operated at $60 \mathrm{kV}$ with $50 \mathrm{~mA}$. The diameter of the pellet used for XRF analysis was $37 \mathrm{~mm}$ and the pellet was prepared by mixing $4 \mathrm{~g}$ of sample with $1 \mathrm{~g}$ of microcrystalline methyl cellulose and by applying $15 \mathrm{~T}$ pressure for one min.

The particle size distribution (PSD) of OPC cement samples was determined by dispersing the cement samples in ethylene glycol medium with refractive index, 1.42857 and using HORIBA LA-300 set up. The real and imaginary part of refractive indices for cement particles were taken as $n_{\text {real }}=1.7$ and $n_{\mathrm{k}}=0.1$, respectively for computing particle size distribution data (Ferraris et al 2004).

\section{Theoretical}

\section{$3.1 \quad X$-ray powder diffraction}

X-ray powder diffractogram of a crystalline material provides a unique diffraction pattern of each material when 
monochromatic X-rays of a given wavelength, $\lambda$, is scattered from the material over a wide range of $2 \theta$ values. The powder diffractogram consists of a series of diffraction peaks each of which is characterized by its position $(2 \theta)$, intensity $(I)$ and Miller indices $(h k l)$ of the set of crystal planes contributing to a particular peak. The characteristic features of the diffractogram can be calculated by using inputs like unit cell parameters $(a, b, c, \alpha, \beta, \gamma)$, space group, fractional position of the atoms in the unit cell, site occupation number and thermal parameters etc. The intensity of the diffraction peak is given by following equation:

$$
I_{\text {cal }}=\left|F_{h k l}\right|^{2} p\left(\frac{1+\cos ^{2} 2 \theta}{\sin ^{2} \theta \cos \theta}\right) e^{-2 M} .
$$

All the parameters are as defined in the text of Cullity (1978).

\subsection{Rietveld refinement method}

Rietveld refinement method (Rietveld 1969; Young et al 1977; Hill and Howard 1987; Bish and Howard 1988; Young 1993; De La Torre et al 2001; Costa and Marchi 2003; Scrivener et al 2004; Taylor and Hinezak 2004) is a very useful method to analyse X-ray diffraction (XRD) data of complex materials. The method fits to a multivariable structurebackground-profile model to the experimental XRD data of the material under investigation. In this method, user defined parameters are optimized using least-square procedure to minimize the difference between the observed (experimental) and calculated diffraction patterns based on approximate crystal structure and instrumental parameters. The scale factor of the phases present in the sample is used to calculate the phase composition of the material (Hill and Howard 1987; Bish and Howard 1988).

The key equations which are used in the implementation of Rietveld method in practice are described below:

The full "multiphase" Rietveld expression for the intensity $y_{i}$ at a point $i$ of the step scan is (Young 1993):

$$
\begin{aligned}
y_{c i}= & {\left[\sum_{j} S_{j} \sum_{h k l_{j}} L_{h k l_{j}}\left|F_{h k l_{j}}\right|^{2} \phi\left(2 \theta_{i}-2 \theta_{h k l_{j}}\right) P_{h k l_{j}} A\right] } \\
& +y_{b i},
\end{aligned}
$$

where $y_{c i}$ is the calculated intensity at point $i, y_{b i}$ the background contribution to intensity at point $i, S_{j}$ the scale factor of phase $j, h k l$ the Miller indices $h k l$ for a Bragg reflection of phase $j, L_{h k l}$ the Lorentz polarization and multiplicity factors, $F_{h k l}$ the structure factor for Bragg reflection $h k l, P_{h k l}$ the preferred orientation function, $A$ the absorption factor and $\phi$ the peak profile function.

The quantity which is minimized in the refinement process is residual $S^{\prime}{ }_{y}$

$$
S_{y}^{\prime}=\sum_{i} w_{i}\left(y_{o i}-y_{c i}\right)^{2},
$$

where, $w_{i}$ is the $1 / y_{o i}, y_{o i}$ the observed intensity at a point $i, y_{c i}$ the calculated intensity at a point $i$.

In practice, the different ' $R$ ' factors like $R_{\mathrm{p}}, R_{\mathrm{wp}}, R_{\text {exp }}$ and ' $\chi$ ' $\left(R_{\mathrm{wp}} / R_{\mathrm{exp}}\right)$ are used to estimate the goodness of fit (Young 1993; Rodríguez-Carvajal, Fullprof 2000).

3.2a Quantitative phase analysis: The quantitative phase analysis in Rietveld method relies on the following relationship (Hill and Howard 1987; Bish and Howard 1988).

$$
W_{p}=S_{p}(Z M V)_{p} / \sum_{i=1}^{n} S_{i}(Z M V)_{i},
$$

where $W_{\mathrm{p}}$ is the relative weight fraction of phase $p$ in a mixture of $n$ phases, S, Z, M and V are Rietveld scale factor, number of formula units per unit cell, mass of the formula unit (in atomic mass units) and volume of the unit cell, respectively.

\subsection{Mathematical modeling of hydration of tricalcium silicate $\left(C_{3} S\right)$ particles}

In order to understand the hydration process of OPC cement particles we have studied theoretically the hydration of spherical $\mathrm{C}_{3} \mathrm{~S}$ particles as $\mathrm{C}_{3} \mathrm{~S}$ is the major component of OPC cement. The $\mathrm{C}_{3} \mathrm{~S}$ hydration model used in this work was developed by Pommersheim and Clifton (1979, 1982). In this model it is assumed that the hydrating particles remain isothermal during the hydration process and their hydration rates do not depend upon their positions in the system. These particles are considered to be uniform in size and spherical in shape. The hydration products that formed around the particles are also assumed to have spherical symmetry. Two distinct calcium silicate hydrate layers are formed around the hydrating particles, an inner hydrate layer which grows inward from the original boundary (radius $R$ ) of the $\mathrm{C}_{3} \mathrm{~S}$ particle and outer layer which grows outward in the pore solution.

Application of appropriate boundary and interface conditions to diffusion of chemical species through these hydrate layers yields the following differential equation:

$$
-\frac{\mathrm{d} t}{\tau}=\left[\left(\frac{1}{m y^{2}}+\frac{1}{y}-1\right)+\frac{D_{i}}{D_{x}} \frac{x}{R}+\frac{D_{i}}{D_{o}}\left(1-\frac{R}{r_{o}}\right)\right] y^{2} d y,
$$

where $\tau$ is the characteristic time defined as $a R^{2} \rho / C_{o} D_{i}$ and $y$ the reduced radius, $r_{i} / R, a$ the number of moles of water reacted per mole of $\mathrm{C}_{3} \mathrm{~S}$ consumed, $\rho$ the molar density of $\mathrm{C}_{3} \mathrm{~S}$ particle, $R$ the original radius of the particle, $r_{i}$ and $r_{o}$ are the inner and outer radii of the hydrating $\mathrm{C}_{3} \mathrm{~S}$ particle, $D_{i}, D_{x}$ and $D_{o}$ are the diffusivities through inner, middle and outer hydrate layer, respectively, $m$ the reaction-diffusion modulus given by $k R / D_{i}$ and $k$ the first order surface rate constant for the reaction between $\mathrm{C}_{3} \mathrm{~S}$ and water. 
The solution of the above differential equation with initial condition $y=1$ at $t=0$, predicts the radius of the unhydrated $\mathrm{C}_{3} \mathrm{~S}$ core $\left(r_{i}\right)$ and the degree of hydration $(\alpha)$ as a function of time. $\alpha$ is given by following equation:

$$
\alpha=1-y^{3} .
$$

\section{Computational procedure}

\subsection{Computation of X-ray powder diffraction profiles of cement components and quantitative phase analysis of OPC cement using Rietveld refinement method}

The crystallographic software 'Fullprof 2000' (RodríguezCarvajal, Fullprof 2000) was used in this study to compute the theoretical X-ray diffraction patterns of polymorphs of the different components that are generally present in OPC cement. X-ray $\mathrm{CuK}_{\alpha 1}$ wavelength $(1.540560 \AA)$ was used in the computation of the X-ray diffraction patterns. The unit cell parameters $(a, b, c, \alpha, \beta$ and $\gamma)$, space group and crystallographic phases of different compounds of different components of interest are listed in table 1. The other input parameters required for computation of diffraction patterns like fractional atomic position of the atoms in the unit cell, site occupation number and thermal displacement parameters etc of individual phases are available in references cited in table 1. As "Fullprof" accepts anisotropic thermal displacement parameter only in $\beta$ form, other forms of this parameter like U's and B's in different literature have to be converted first to $\beta$ form before computation of X-ray diffraction pattern. Later, Rietveld refinement process was carried out using the same software for quantitative phase analysis of OPC cement samples.

For quantitative phase analysis of X-ray diffractograms of OPC cement samples, we have included seven phases viz. $M_{3}$-alite (Mumme 1995), $\beta-\mathrm{C}_{2} \mathrm{~S}$, both cubic and orthorhombic (Nishi and Takeuchi 1975) $\mathrm{C}_{3} \mathrm{~A}$ and brownmillerite along with minor phases like gypsum and calcium sulphate hemihydrate in the Rietveld refinement process. The backgrounds of the patterns were fitted with six-coefficient polynomial background function. The pseudo-Voigt function $(\mathrm{pV})$ was used to fit the diffraction peaks of all included phases. The modified March's function was used to account for strong preferred orientation exhibited by gypsum phase.

Table 1. Crystallographic data for crystalline phases present in cement and clinker.

\begin{tabular}{|c|c|c|c|c|c|c|c|c|c|c|}
\hline No. & $\begin{array}{l}\text { Chemical } \\
\text { composition }\end{array}$ & Phase & $\begin{array}{l}\text { Space } \\
\text { group }\end{array}$ & $a(\AA)$ & $b(\AA)$ & $c(\AA)$ & $\alpha$ & $\beta$ & $\gamma$ & Reference \\
\hline \multicolumn{11}{|c|}{ Major phases } \\
\hline 1. & $\begin{array}{l}\text { Alite } \\
\mathrm{Ca}_{2.99} \mathrm{Na}_{0.01}\left(\mathrm{Si}_{0.90}\right. \\
\mathrm{Al}_{0.04} \mathrm{Fe}_{0.02} \mathrm{P}_{0.03} \\
\left.\mathrm{Mg}_{0.05}\right) \mathrm{O}_{5}\end{array}$ & Monoclinic $M_{3}$ & $\mathrm{Cm}$ & $12 \cdot 235$ & $7 \cdot 073$ & $9 \cdot 298$ & $90 \cdot 0$ & $116 \cdot 3$ & $90 \cdot 0$ & $\begin{array}{l}\text { (Mumme 1995; } \\
\text { Peterson 2003) }\end{array}$ \\
\hline 2. & $\mathrm{Ca}_{3}\left(\mathrm{SiO}_{4}\right) \mathrm{O}$ & Triclinic $T_{1}$ & $P-1$ & 11.67 & $14 \cdot 24$ & $13 \cdot 72$ & $105 \cdot 5$ & $94 \cdot 3$ & $90 \cdot 0$ & $\begin{array}{l}\text { (Golovastikov et al 1975; } \\
\text { Peterson 2003) }\end{array}$ \\
\hline 3. & $\begin{array}{l}\mathrm{Ca}_{2 \cdot 98} \mathrm{Si}_{0 \cdot 98} \\
\mathrm{Al}_{0.04} \mathrm{O}_{5} \\
\text { Belite }\end{array}$ & Rhombohedral $R$ & $R 3 \mathrm{~m}$ & $7 \cdot 135$ & $7 \cdot 135$ & $25 \cdot 586$ & $90 \cdot 0$ & $90 \cdot 0$ & $120 \cdot 0$ & (Nishi and Takeuchi 1984) \\
\hline $4 . \quad 1$ & $\beta-\mathrm{Ca}_{2} \mathrm{SiO}_{4}$ & Monoclinic & $P 21 / n$ & $5 \cdot 502$ & $6 \cdot 745$ & $9 \cdot 297$ & $90 \cdot 0$ & 94.59 & $90 \cdot 0$ & (Jost et al 1977) \\
\hline 5. & $\begin{array}{l}\gamma-\mathrm{Ca}_{2} \mathrm{SiO}_{4} \\
\text { Tricalcium aluminate }\end{array}$ & Orthorhombic & Pbnm & $5 \cdot 081$ & $11 \cdot 224$ & $6 \cdot 778$ & $90 \cdot 0$ & $90 \cdot 0$ & $90 \cdot 0$ & (Udagawa et al 1980) \\
\hline 6. & $\mathrm{Ca}_{3} \mathrm{Al}_{2} \mathrm{O}_{6}$ & Cubic & $P a 3$ & $15 \cdot 263$ & $15 \cdot 263$ & $15 \cdot 263$ & $90 \cdot 0$ & $90 \cdot 0$ & $90 \cdot 0$ & (Mondal and Jeffery 1975) \\
\hline 7. & $\mathrm{Ca}_{8.5} \mathrm{NaAl}_{6} \mathrm{O}_{18}$ & Orthorhombic & $P b c a$ & $10 \cdot 868$ & $10 \cdot 856$ & $15 \cdot 128$ & $90 \cdot 0$ & $90 \cdot 0$ & $90 \cdot 0$ & $\begin{array}{l}\text { (Nishi and Takeuchi 1975; } \\
\text { Peterson 2003) }\end{array}$ \\
\hline 8. & $\begin{array}{l}\text { Calcium aluminoferrit } \\
\text { Brownmillerite } \\
\left(\mathrm{Ca}_{2} \mathrm{Fe}_{\mathrm{AlO}}\right)\end{array}$ & Orthorhombic & $\operatorname{Ibm} 2$ & $5 \cdot 584$ & $14 \cdot 60$ & $5 \cdot 374$ & $90 \cdot 0$ & $90 \cdot 0$ & $90 \cdot 0$ & (Colville and Geller 1971) \\
\hline \multicolumn{11}{|c|}{ Minor phases } \\
\hline 9. & $\begin{array}{l}\text { Calcium sulphates } \\
\text { Gypsum: calcium } \\
\text { sulphate dihydrate } \\
\left(\mathrm{CaSO}_{4} \cdot 2 \mathrm{H}_{2} \mathrm{O}\right)\end{array}$ & Monoclinic & $I 2 / c$ & $5 \cdot 6740$ & $15 \cdot 1049$ & 6.4909 & $90 \cdot 0$ & $118 \cdot 513$ & $90 \cdot 0$ & (Schofield et al 1996) \\
\hline 10. & $\begin{array}{l}\text { Calcium sulphate } \\
\text { hemihydrate } \\
\left(\mathrm{CaSO}_{4} \cdot 0 \cdot 5 \mathrm{H}_{2} \mathrm{O}\right) \\
\text { Tripotassium sodium }\end{array}$ & Monoclinic & $I 121$ & $12 \cdot 0344$ & 6.9294 & $12 \cdot 6757$ & $90 \cdot 0$ & $90 \cdot 265$ & $90 \cdot 0$ & (Benzou et al 1995) \\
\hline 11. & $\mathrm{~K}_{3} \mathrm{Na}\left(\mathrm{SO}_{4}\right)_{2}$ & Trigonal & $P-3 m$ & $5 \cdot 6801$ & $5 \cdot 6801$ & $7 \cdot 309$ & $90 \cdot 0$ & $90 \cdot 0$ & $120 \cdot 0$ & (Okada and Ossaka 1980) \\
\hline
\end{tabular}


The most important parameters of refinement process viz. scale factors of all the phases, were refined simultaneously in the first stage itself and kept variable during the subsequent stages of refinement process. The zero point shift and polynomial background coefficients were refined respectively after the first step. In the next step, unit cell parameters $a, b, c$, $\alpha, \beta$ and $\gamma$ were refined. During the refinement, the phases were given priorities as per their general weight percentage and also their scattering power (mass absorption coefficient, $\mu / \rho$ ). Peak width parameter ' $W$ ' was also refined for all the phases in the same sequence.

In the second stage of the refinement process, fractional atomic positions for heavier atoms like $\mathrm{Ca}$ and $\mathrm{Si}$ are refined only for two major phases viz. alite and belite. The occupation number was refined for all the atoms of both the phases. The parameters for the preferred orientation of the gypsum phase were refined first and then the refinement of the asymmetric peak shape parameters for the alite and belite was carried out. Finally peak shape parameters viz. $U, V$ and $\eta$ of pseudo-Voigt function were refined.

\subsection{Computation of mass percentage of components from XRF data of cement composition}

At the first stage of analysis, Bogue method (Bogue 1955; Hewlett 1988; American Standard ASTM C 150-94) was used to calculate the approximate mineralogical composition of the OPC cement samples from the elemental composition of the samples which were determined by XRF method. The formulae (Hewlett 1988) used for calculation of mass percentage of four major phases viz. $\mathrm{C}_{3} \mathrm{~S}, \mathrm{C}_{2} \mathrm{~S}, \mathrm{C}_{3} \mathrm{~A}$
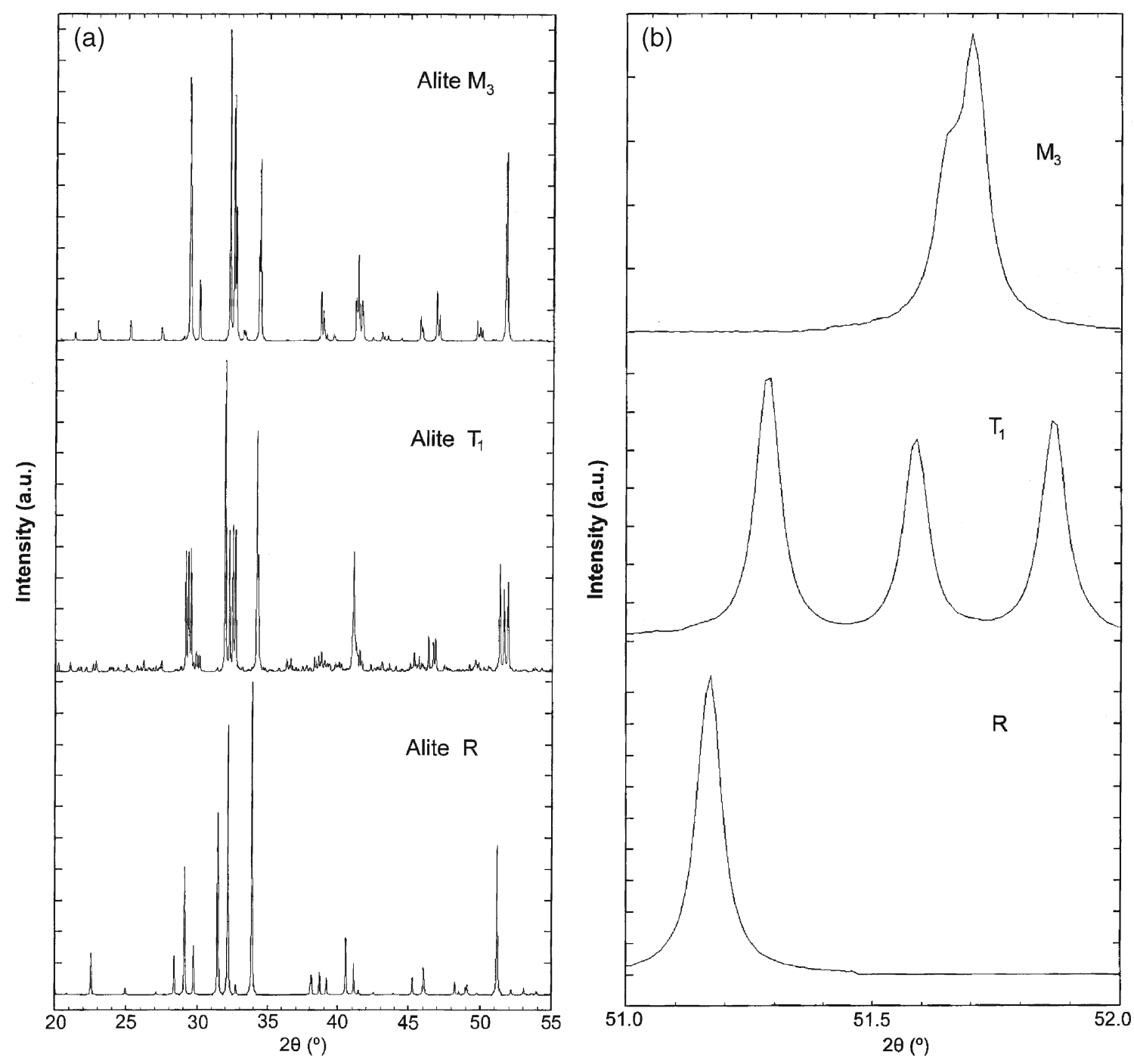

Figure 1. a. Computed diffractograms of alite polymorphs: monoclinic $\left(M_{3}\right)$, triclinic $\left(T_{1}\right)$ and rhombohedral $(R)$ and b. alite peaks around $2 \theta=51^{\circ}-52^{\circ}$ of computed diffractograms of monoclinic $\left(M_{3}\right)$, triclinic $\left(T_{1}\right)$ and rhombohedral $(R)$. 
and $\mathrm{C}_{4} \mathrm{AF}$ of cement samples are given below (American Standard ASTM C 150-94).

$$
\begin{aligned}
\mathrm{C}= & \% \mathrm{CaO}, \mathrm{S}=\% \mathrm{SiO}_{2}, \mathrm{~A}=\% \mathrm{Al}_{2} \mathrm{O}_{3}, \\
\mathrm{~F}= & \% \mathrm{Fe}_{2} \mathrm{O}_{3}, \hat{\mathrm{S}}=\% \mathrm{SO}_{3}, \\
\mathrm{C}_{3} \mathrm{~S}= & 4.071 \times \mathrm{C}-7.600 \times \mathrm{S}-6.718 \times \mathrm{A} \\
& -1.430 \times \mathrm{F}-2.857 \times \hat{\mathrm{S}},
\end{aligned}
$$

$$
\mathrm{C}_{2} \mathrm{~S}=2.867 \times \mathrm{S}-0.754 \times \mathrm{C}_{3} \mathrm{~S}
$$

$$
\mathrm{C}_{3} \mathrm{~A}=2.65 \times \mathrm{A}-1.692 \times \mathrm{F},
$$

$$
\mathrm{C}_{4} \mathrm{AF}=3 \cdot 043 \times \mathrm{F},
$$

where the $\% \mathrm{CaO}, \% \mathrm{SiO}_{2}$ etc are the mass percentage of the component oxides.

\section{Results and discussion}

The input data required for computation of X-ray powder diffractograms of different component phases of cement and clinker are provided in table 1 where the crystal structure data of 11 samples of alite, belite, aluminate, ferrite, gypsum, calcium sulphate hemihydrate and tripotassium sodium disulphate along with their chemical composition, type of crystal structures, space group and unit cell parameters etc are summarized. The other set of input data required for computation of diffraction pattern are fractional atomic position, site occupation number and thermal displacement parameters. These data for each phase are taken from the corresponding references cited in the last column of table 1 .

The computed diffractograms of each individual phase of each component of cement and clinker are presented in graphical form ( $2 \theta$ vs $I)$ in figures $1-6$.

\subsection{Characteristic and distinguishing features of different cement components}

To facilitate the discussion of polymorphs of each component phase, we have presented the results in comparative figures. For example, figure 1a shows the computed diffractograms of three polymorphs of alite phases viz. monoclinic $\left(M_{3}\right)$, triclinic $\left(T_{1}\right)$ and rhombohedral $(R)$ computed over $2 \theta$ angle varying from $20^{\circ}$ to $55^{\circ}$ for comparison among these polymorphs and also with experimental X-ray diffractograms of OPC cement samples. The unique distinguishing diffraction peaks of these polymorphs of alite are shown in figure $1 \mathrm{~b}$. The $M_{3}$ phase of alite shows a doublet at $2 \theta=51.7^{\circ}$ whereas
$T_{1}$ phase of alite shows a triplet at $51^{\circ}-52^{\circ}$ and rhombohedral $R$ phase shows strong singlet at $51 \cdot 16^{\circ}$. The diffraction pattern computed from monoclinic structure given by Mumme (Mumme 1995; Peterson 2003) shows a shoulder and a peak at $2 \theta=51.7^{\circ}$ instead of well resolved doublet as observed in the case of pure $M_{3}$ phase given by Nishi (Taylor 1997) which, however, is not computed here. This difference in the distinguishing features can be attributed to difference in the chemical composition of the two alite phases. The relatively lower $\mathrm{Mg}$ content $(0.05 \%)$ (atomic percentage) in alite $M_{3}$ (Mumme 1995) is responsible for this average structure compared to that of pure alite $M_{3}$ phase given by Nishi which has about 0.11\% MgO (Taylor 1997). The pure $M_{1}$ phase of alite, which is not computed here,

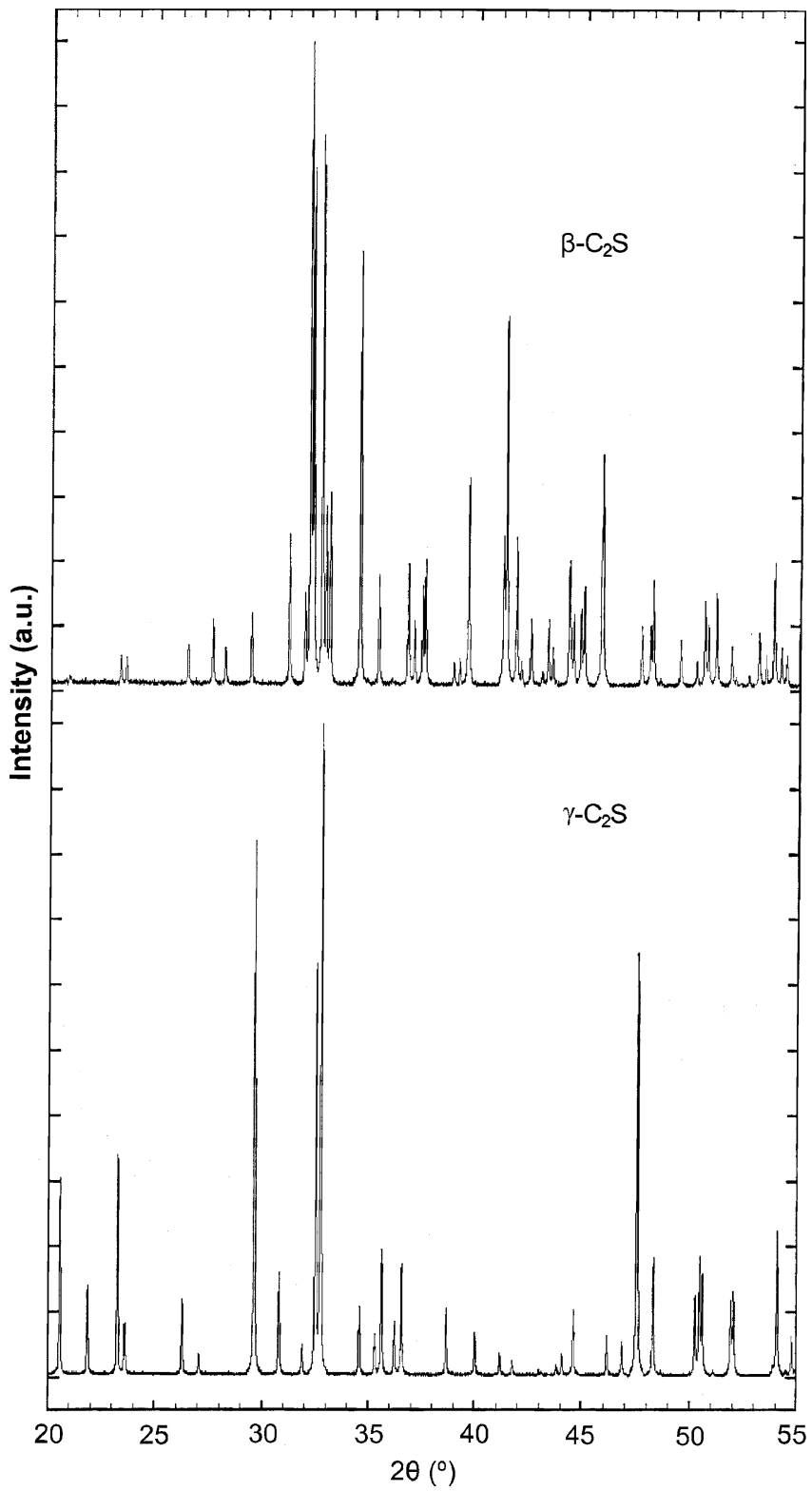

Figure 2. Computed diffractograms of belite polymorphs: $\beta-\mathrm{C}_{2} \mathrm{~S}$ and $\gamma-\mathrm{C}_{2} \mathrm{~S}$. 


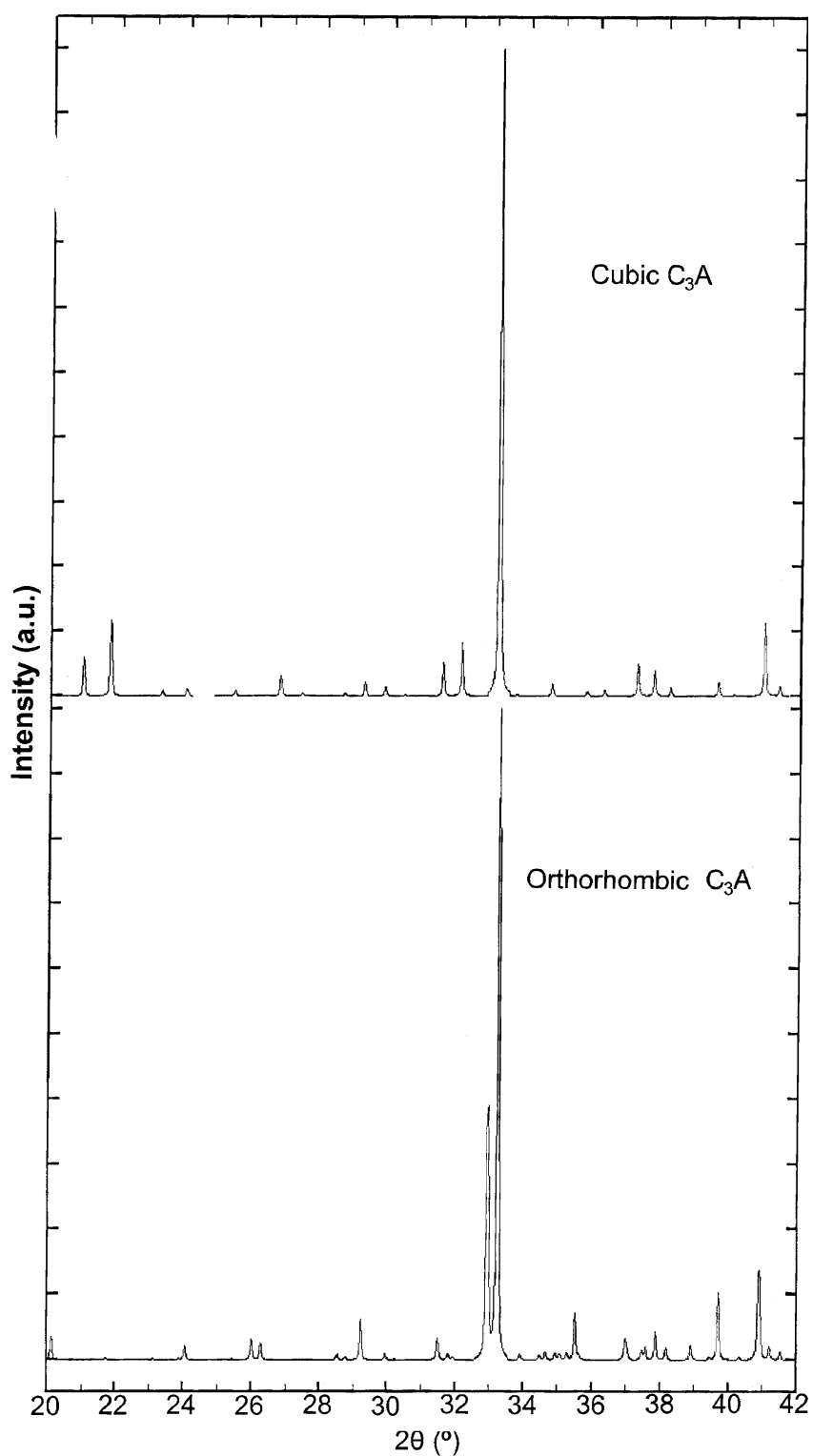

Figure 3. Computed diffractograms of tricalcium aluminate polymorphs: cubic and orthorhombic $\mathrm{C}_{3} \mathrm{~A}$.

shows a well defined singlet at $2 \theta=51.7^{\circ}$ (Taylor 1997). Figure 2 shows comparative diffractograms of two important belite phases viz. $\beta-\mathrm{C}_{2} \mathrm{~S}$ and $\gamma-\mathrm{C}_{2} \mathrm{~S}$, computed in the range of $2 \theta$ values from $20^{\circ}$ to $55^{\circ}$. For $\beta-\mathrm{C}_{2} \mathrm{~S}$ all the major peaks overlap with the $M_{3}$ phase of alite with the exception of distinct peaks at $2 \theta$ values of $31.10^{\circ}$ and $35.29^{\circ}$ which may be used for quantitative analysis of that phase in cement, if the intensity is clearly measurable in actual cement. $\gamma-\mathrm{C}_{2} \mathrm{~S}$ phase can be differentiated from $\beta-\mathrm{C}_{2} \mathrm{~S}$ phase by the unique distinguishing peak at $2 \theta=29.63^{\circ}, 47.53^{\circ}$. It should be noted that $\gamma-\mathrm{C}_{2} \mathrm{~S}$ phase has inferior hydraulic property and therefore, this phase is undesirable in cement clinker at the cost of $\beta-C_{2}$ S phase (Udagawa et al 1980; Stutzman 1996).

Figure 3 shows comparative diffractograms of cubic and orthorhombic tricalcium aluminate phase. The cubic phase

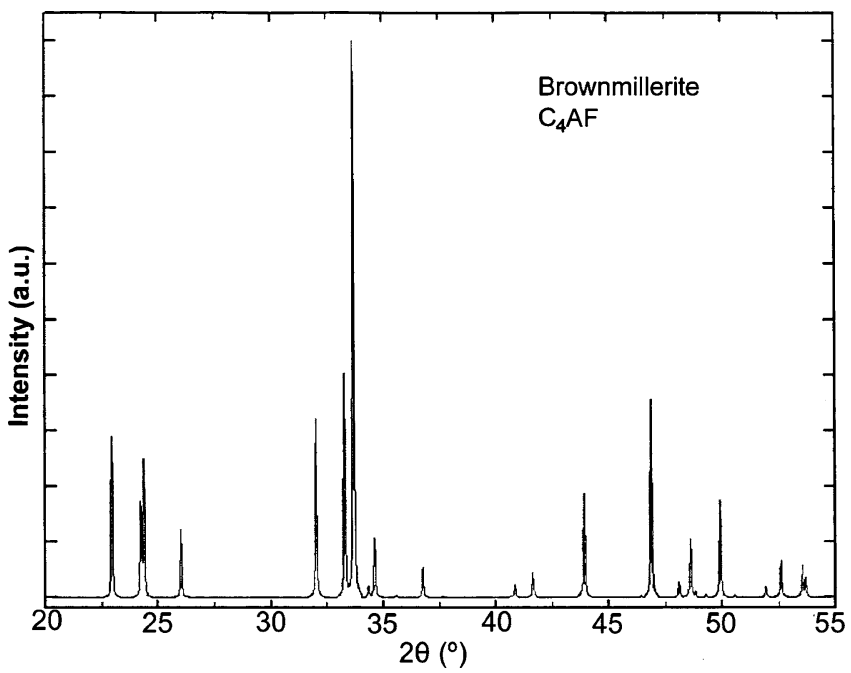

Figure 4. Computed diffractograms of brownmillerite $\left(\mathrm{C}_{4} \mathrm{AF}\right)$.

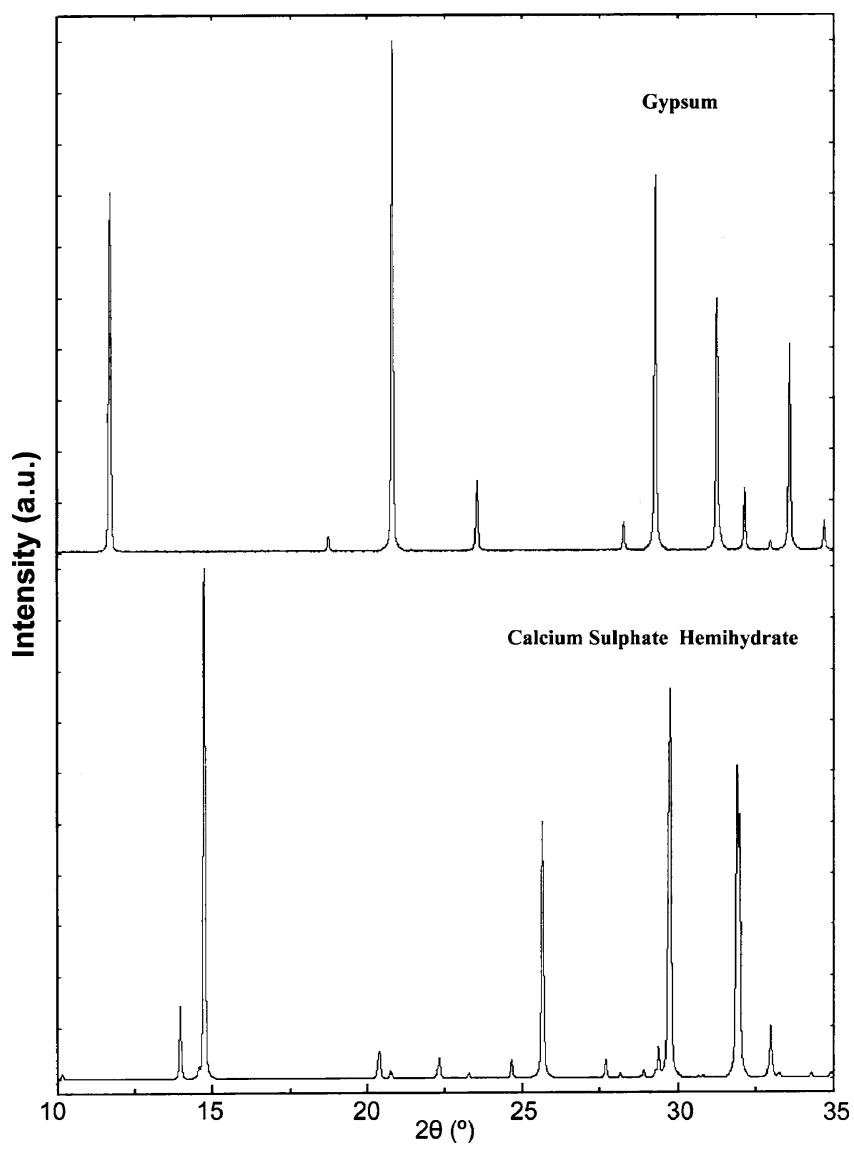

Figure 5. Computed diffractograms of gypsum and calcium sulphate hemihydrate.

of $\mathrm{C}_{3} \mathrm{~A}$ is characterized by a strong peak at $33.17^{\circ}$ which falls in the overlap zone of the OPC cement $\left(2 \theta=30^{\circ}\right.$ to $35^{\circ}$ ). The orthorhombic phase of $\mathrm{C}_{3} \mathrm{~A}$ can be differentiated from the cubic phase of $\mathrm{C}_{3} \mathrm{~A}$ by the presence of a doublet with peak position at $32.95^{\circ}$ and $33.23^{\circ}$ in place of strong 


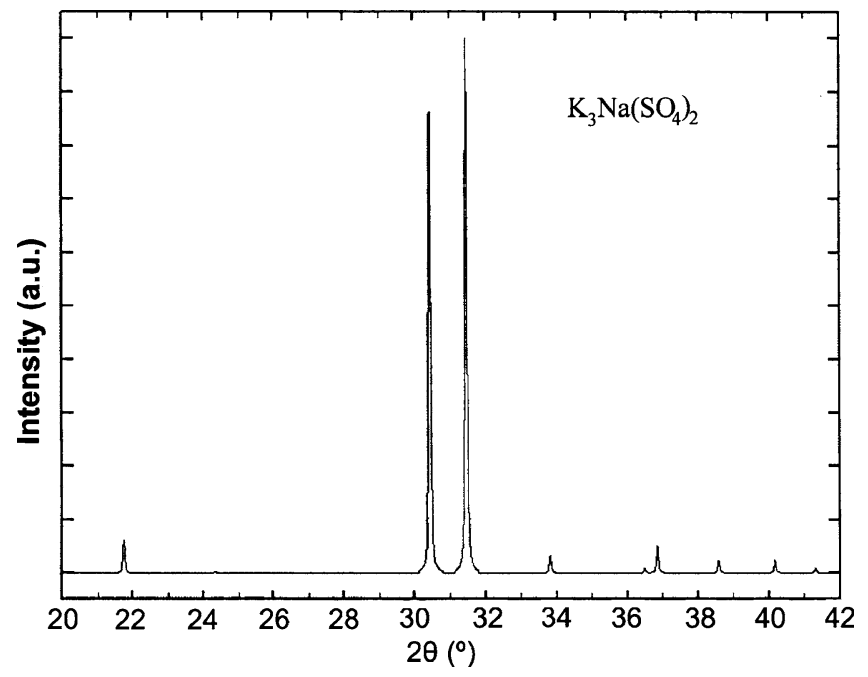

Figure 6. Computed diffractograms of tripotassium sodium disulphate, $\mathrm{K}_{3} \mathrm{Na}\left(\mathrm{SO}_{4}\right)_{2}$.

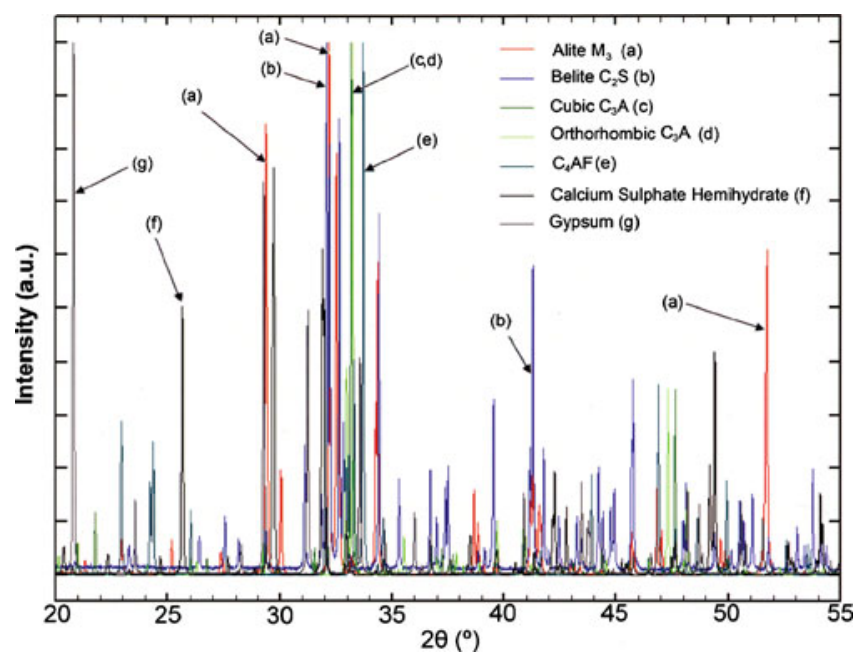

Figure 7. Superposition of X-ray diffractograms of alite $M_{3}$, belite $\beta-\mathrm{C}_{2} \mathrm{~S}$, cubic and orthorhombic $\mathrm{C}_{3} \mathrm{~A}$, brownmillerite $\mathrm{C}_{4} \mathrm{AF}$, gypsum and calcium sulphate hemihydrate.

Table 2. Distinguishing features of computed diffractograms of different components present in cementitious materials.

\begin{tabular}{|c|c|c|c|}
\hline Phase & Polymorphs & P.D.F. card no. & Distinct features of diffractograms \\
\hline \multirow[t]{4}{*}{ Alite $\left(\mathrm{C}_{3} \mathrm{~S}\right)$} & Monoclinic $M_{3}$ & $42-551$ & Strong peak with a shoulder at $51.7^{\circ}$ \\
\hline & Triclinic $T_{1}$ & $31-301$ & $\begin{array}{l}\text { Triplet between } 51-52^{\circ} \\
\left(51.3^{\circ}, 51.58^{\circ} \text { and } 51.85^{\circ}\right)\end{array}$ \\
\hline & Rhombohedral, R & $16-406$ & Strong singlet at $51 \cdot 16^{\circ}$ \\
\hline & \multicolumn{3}{|c|}{$\begin{array}{l}\text { For } M_{3} \text { phase, major peaks at } 29.35^{\circ} \text { and } 51.7^{\circ} \text { are essentially free } \\
\text { from overlap and may be used for identification and quantitative analysis }\end{array}$} \\
\hline \multirow[t]{3}{*}{ Belite $\left(\mathrm{C}_{2} \mathrm{~S}\right)$} & $\beta-\mathrm{C}_{2} \mathrm{~S}$ & $33-302$ & $\begin{array}{l}\text { Strong peaks at } 32 \cdot 05^{\circ}, 32 \cdot 61^{\circ} 34.40^{\circ} \\
\text { and } 41.28^{\circ}\end{array}$ \\
\hline & \multicolumn{3}{|c|}{$\begin{array}{l}\text { Peak at } 31.10^{\circ} \text { and } 35.30^{\circ} \text { are weak, but essentially free from overlap } \\
\text { and can be used for quantitative analysis }\end{array}$} \\
\hline & $\gamma-\mathrm{C}_{2} \mathrm{~S}$ & $31-297$ & Strong peaks at $32.72^{\circ}, 29.63^{\circ}$ and $47.53^{\circ}$ \\
\hline \multirow[t]{4}{*}{ Tricalcium aluminate $\left(\mathrm{C}_{3} \mathrm{~A}\right)$} & Cubic & $38-1429$ & $\begin{array}{l}\text { Strong peak at } 33 \cdot 17^{\circ} \text { may be used for } \\
\text { identification }\end{array}$ \\
\hline & \multicolumn{3}{|c|}{$\begin{array}{l}\text { Peak at } 28.61 \text { is weak, but free from overlap and may be used for } \\
\text { quantitative analysis }\end{array}$} \\
\hline & Orthorhombic & $32-150$ & $\begin{array}{l}\text { Two peaks at } 32 \cdot 95^{\circ} \text { and } 33 \cdot 23^{\circ} \text { are } \\
\text { observed in place of single peak at } \\
33 \cdot 17^{\circ} \text { as observed in cubic case }\end{array}$ \\
\hline & \multicolumn{3}{|c|}{$\begin{array}{l}\text { Major peaks } 33.23^{\circ} \text { is in the region of overlap and difficult to use } \\
\text { for quantitative purpose }\end{array}$} \\
\hline \multirow[t]{2}{*}{$\begin{array}{l}\text { Calcium aluminoferrite } \\
\left(\mathrm{Ca}_{2}\left(\mathrm{Fe}_{x} \mathrm{Al}_{1-x}\right)_{2} \mathrm{O}_{5}\right)\end{array}$} & $\begin{array}{r}\mathrm{C}_{4} \mathrm{AF}-\mathrm{Ca}_{2} \mathrm{FeAlO}_{5} \\
\text { (Brownmillerite) }\end{array}$ & $30-226$ & $\begin{array}{l}\text { Key diffraction peaks at } 12 \cdot 1^{\circ}, 24 \cdot 4^{\circ} \\
\text { and } 33 \cdot 7^{\circ}\end{array}$ \\
\hline & \multicolumn{3}{|c|}{ For quantitative analysis suitable peaks at $12 \cdot 1^{\circ}, 24 \cdot 4^{\circ}$ can be used } \\
\hline Calcium sulphate dihydrate (Gypsum) & $\mathrm{CaSO}_{4} \cdot 2 \mathrm{H}_{2} \mathrm{O}$ & $33-311$ & $\begin{array}{l}\text { Key diffraction peaks which can be used for } \\
\text { identification and quantitative analysis } \\
\text { are } 11.71^{\circ}, 20 \cdot 80^{\circ}\end{array}$ \\
\hline $\begin{array}{l}\text { Calcium sulphate hemihydrate } \\
\left(\mathrm{CaSO}_{4} \cdot 0 \cdot 5 \mathrm{H}_{2} \mathrm{O}\right)\end{array}$ & $\mathrm{CaSO}_{4} \cdot 0 \cdot 5 \mathrm{H}_{2} \mathrm{O}$ & $41-224$ & $\begin{array}{l}\text { Key diffraction peak at } 14.73^{\circ} \text { can be used } \\
\text { for identification and quantitative analysis }\end{array}$ \\
\hline Tripotassium sodium disulphate & $\mathrm{K}_{3} \mathrm{Na}\left(\mathrm{SO}_{4}\right)_{2}$ & 20-926 & $\begin{array}{l}\text { Distinct doublet observed at } 30.45^{\circ} \\
\text { and } 31.47^{\circ}\end{array}$ \\
\hline
\end{tabular}


single peak at $33 \cdot 17^{\circ}$ as observed for cubic case. It may be noted that the incorporation of $\mathrm{Na}_{2} \mathrm{O}$ in cubic $\mathrm{C}_{3} \mathrm{~A}$ beyond $1 \%$ causes the transformation of cubic phase to orthorhombic $\mathrm{C}_{3} \mathrm{~A}$ phase (Taylor 1997). However, it is difficult to identify individual aluminate phases in actual cement diffractograms. For "Brownmillerite $\left(\mathrm{C}_{4} \mathrm{AF}\right)$ " phase of aluminoferrite (figure 4), the key differentiating peaks are located at $12 \cdot 10^{\circ}$, $24.4^{\circ}$ and $33.7^{\circ}$ and the first two peaks may be used for quantitative analysis as the peak at $33.7^{\circ}$ falls in the overlap zone.

The comparative diffractograms of gypsum and calcium sulphate hemihydrate are shown in figure 5. Gypsum phase in cement can be identified by the distinguishing peaks at

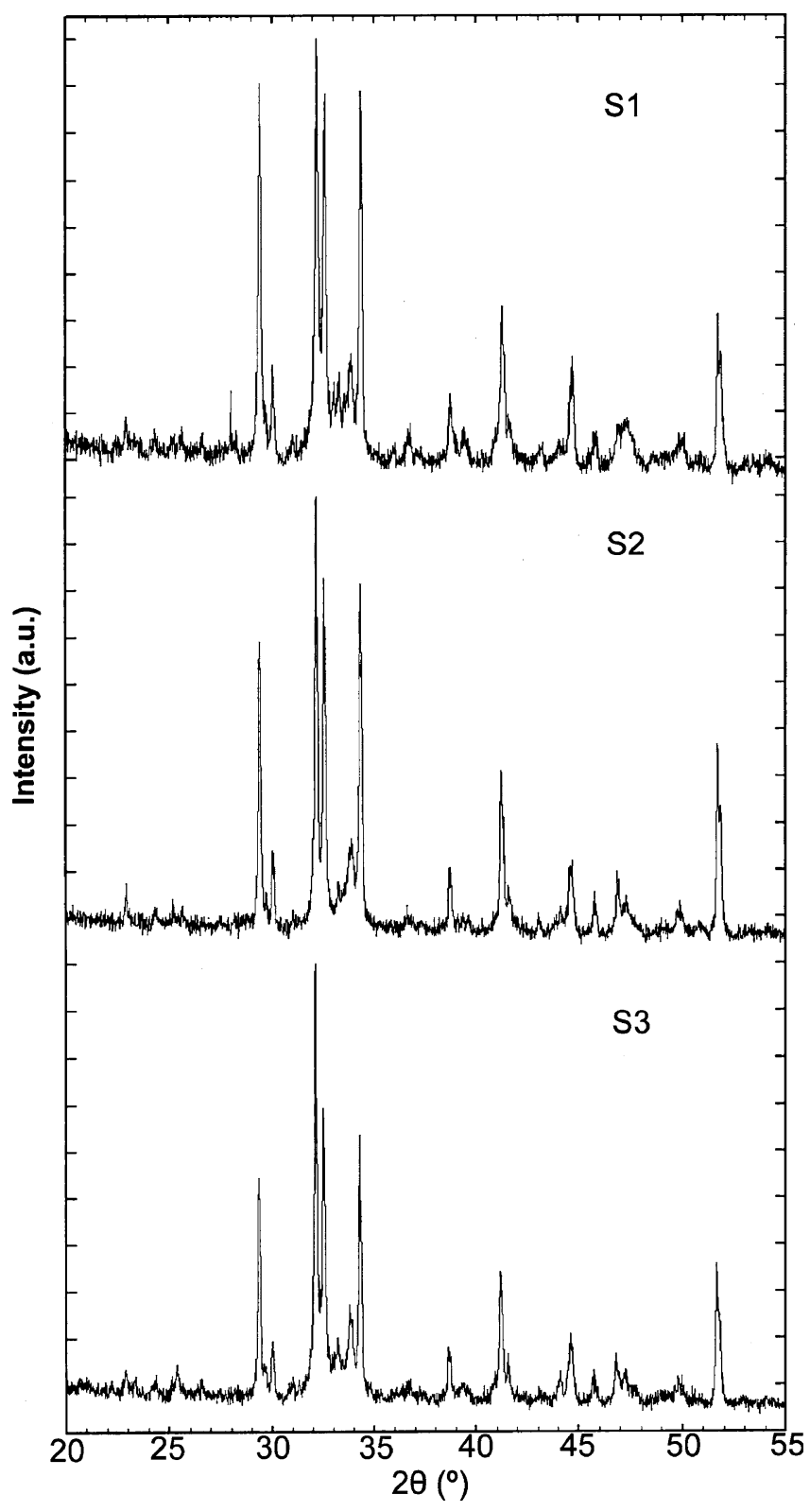

Figure 8. Experimental X-ray diffractograms of OPC cement samples $S 1, S 2$ and $S 3$. $11.71^{\circ}$ and $20 \cdot 80^{\circ}$. Similarly, the hemihydrate phase can be identified by a strong distinguishing peak at $14.73^{\circ}$. The other minor phase, tripotassium sodium disulphate (figure 6 ) which shows a distinct doublet at $30.45^{\circ}$ and $31.47^{\circ}$ may be identified by these peaks. But it is difficult to identify this phase in cement because the angular position of the doublet falls in the overlap zone.

The key distinguishing features of each phase is summarized in table 2. The computed data of all the compounds have been compared with X-ray powder diffraction data file to validate the computed results (Stutzman 1996).

\subsection{Qualitative analysis of cement samples}

In order to compare the computed diffraction data of individual component phases and also to analyse the experimental X-ray powder diffractogram of OPC cement, we have superposed the calculated diffraction patterns of seven component phases viz. $M_{3}$ phase of alite, $\beta$ phase of belite, both cubic and orthorhombic phases of aluminate, brownmillerite phase $\left(\mathrm{C}_{4} \mathrm{AF}\right)$ of aluminoferrite, gypsum and calcium sulphate hemihydrate in the angular range of $2 \theta$ values of $20^{\circ}$ to $55^{\circ}$ as shown in figure 7 . Different colour codes are used in figure 7 to differentiate the different components. In this superposed figure, all phases are normalized to $100 \%$ so that the extent of overlap of individual phase in a peak can be computed easily. When figure 7 is compared with the experimental diffractograms of cement samples $S 1, S 2$ and $S 3$ (figure 8), several key features become quite obvious.

It is quite evident from figure 7, that the strongest Bragg's peaks of most of the component phases overlap strongly with each other in the angular range of $30^{\circ}$ to $35^{\circ}$, making it very difficult to use this important part of the OPC cement diffractogram for identification of the phases present in cement. The monoclinic $M_{3}$ phase of "alite" has a major characteristic peak at $2 \theta=29.35^{\circ}$ which is essentially free from overlap of $\beta-\mathrm{C}_{2} \mathrm{~S}$ phase and hence this peak may be used for quantitative analysis of " $M_{3}$ alite" phase in cement and in cement hydration products and also to determine the degree of hydration of cement when an internal standard is used with cement reaction products. The $\beta-\mathrm{C}_{2} \mathrm{~S}$ phase has a medium strong

Table 3. Elemental composition of OPC cement samples by $\mathrm{X}$-ray fluorescence spectroscopy.

\begin{tabular}{lccc}
\hline & \multicolumn{3}{c}{ OPC cement } \\
\cline { 2 - 4 } Oxides & $S 1$ & $S 2$ & $S 3$ \\
\hline $\mathrm{CaO}$ & 64.40 & $66 \cdot 47$ & 63.98 \\
$\mathrm{SiO}_{2}$ & 21.25 & 21.20 & 21.34 \\
$\mathrm{Al}_{2} \mathrm{O}_{3}$ & $5 \cdot 35$ & $5 \cdot 31$ & $5 \cdot 34$ \\
$\mathrm{Fe}_{2} \mathrm{O}_{3}$ & 4.00 & 4.11 & 4.68 \\
$\mathrm{~K}_{2} \mathrm{O}$ & $0 \cdot 35$ & $0 \cdot 37$ & 0.29 \\
$\mathrm{MgO}$ & 1.27 & 0.94 & 0.88 \\
$\mathrm{Na}_{2} \mathrm{O}$ & 0.39 & 0.10 & 0.18 \\
$\mathrm{SO}_{3}$ & 1.54 & 1.69 & 2.45 \\
\hline
\end{tabular}


peak at $41.28^{\circ}$ which although has some overlap with alite phase, may also be explored for quantitative analysis as the $\%$ of contribution of $\beta-\mathrm{C}_{2} \mathrm{~S}$ and $\mathrm{C}_{3} \mathrm{~S}$ to this peak are roughly $62 \%$ and $28 \%$, respectively. Since all the major peaks of $\mathrm{C}_{4} \mathrm{AF}$, cubic and orthorhombic $\mathrm{C}_{3} \mathrm{~A}$ lie in the range $30^{\circ}$ to $35^{\circ}$, it is very difficult to identify these phases separately in cement. The striking similarity of $M_{3}$ alite phase (figure 1a) with OPC cement samples (figure 8) clearly indicates that the alite phase that is present in cement samples $S 1, S 2$ and $S 3$ is monoclinic $M_{3}$ alite phase. The pure $\mathrm{C}_{3} \mathrm{~S}$ phase, which is the triclinic ' $T_{1}$ ' phase and the rhombohedral ' $R$ ' phase of alite are essentially absent in all the samples analysed in this study. The strong similarity of the peak at $41.28^{\circ}$ of $\beta$ $\mathrm{C}_{2} \mathrm{~S}$ and the cement samples indicates that the belite phase present in all the samples is $\beta-\mathrm{C}_{2} \mathrm{~S}$ phase. The absence of strong characteristic peaks of $\gamma$ phase of belite indicates that this phase is essentially absent in all the samples. The strong peaks of all the four major components overlap strongly in the $2 \theta$ region of $31^{\circ}-35^{\circ}$ leading to 4 major peaks in OPC cement as shown in figure 8 . However, this region is difficult to resolve and therefore, is less useful for analysis of cement components.

\subsection{Quantitative analysis of cement samples}

5.3a Bogue method: In the first stage of the quantitative phase analysis of three OPC cement samples, the mass percentages of four major components have been computed by Bogue formulae from the elemental composition of the samples which was determined by XRF spectroscopy (table 3 ). The results are summarized in table 4 along with the phase composition data computed from Rietveld analysis of X-ray diffractograms of the samples.

Table 4. Comparison of phase composition data of OPC cement samples by Rietveld refinement and Bogue methods.

\begin{tabular}{|c|c|c|c|c|c|c|c|}
\hline \multirow{2}{*}{ Phases } & & \multicolumn{2}{|c|}{$S 1$} & \multicolumn{2}{|c|}{$S 2$} & \multicolumn{2}{|c|}{$S 3$} \\
\hline & & Rietveld & Bogue & Rietveld & Bogue & Rietveld & Bogue \\
\hline \multicolumn{2}{|l|}{ Alite } & $58 \cdot 31$ & $54 \cdot 64$ & $59 \cdot 97$ & $63 \cdot 14$ & $50 \cdot 12$ & $48 \cdot 72$ \\
\hline \multicolumn{2}{|l|}{ Belite } & $19 \cdot 65$ & $19 \cdot 70$ & $19 \cdot 29$ & $13 \cdot 16$ & $21 \cdot 41$ & $24 \cdot 43$ \\
\hline \multicolumn{2}{|l|}{$\mathrm{C}_{3} \mathrm{~A}$ (Ortho) } & $4 \cdot 22$ & $7 \cdot 40$ & $0 \cdot 76$ & $7 \cdot 11$ & $7 \cdot 67$ & $6 \cdot 23$ \\
\hline \multicolumn{2}{|l|}{$\mathrm{C}_{3} \mathrm{~A}$ (Cubic) } & $3 \cdot 54$ & & $9 \cdot 31$ & & $9 \cdot 60$ & \\
\hline \multicolumn{2}{|l|}{$\mathrm{C}_{4} \mathrm{AF}$ (Brownmillerite) } & 8.64 & $12 \cdot 17$ & 8.71 & $12 \cdot 51$ & $6 \cdot 31$ & $14 \cdot 24$ \\
\hline \multicolumn{2}{|l|}{ Gypsum } & $1 \cdot 17$ & - & $0 \cdot 0$ & - & $1 \cdot 27$ & - \\
\hline \multicolumn{2}{|l|}{ Hemihydrate } & $4 \cdot 48$ & - & 1.97 & - & $3 \cdot 62$ & - \\
\hline \multicolumn{2}{|l|}{ Total } & $100 \cdot 0$ & $93 \cdot 91$ & $100 \cdot 0$ & $95 \cdot 92$ & $100 \cdot 0$ & $93 \cdot 62$ \\
\hline \multirow[t]{4}{*}{ L. S. refinement factors } & $R_{\mathrm{p}}$ & $8 \cdot 77$ & & 9.41 & & $8 \cdot 96$ & \\
\hline & $R_{\mathrm{wp}}$ & $11 \cdot 3$ & & $12 \cdot 0$ & & $11 \cdot 3$ & \\
\hline & $R_{\exp }$ & $8 \cdot 39$ & & $9 \cdot 14$ & & $8 \cdot 38$ & \\
\hline & $\chi^{2}$ & 1.81 & & 1.93 & & $1 \cdot 83$ & \\
\hline
\end{tabular}

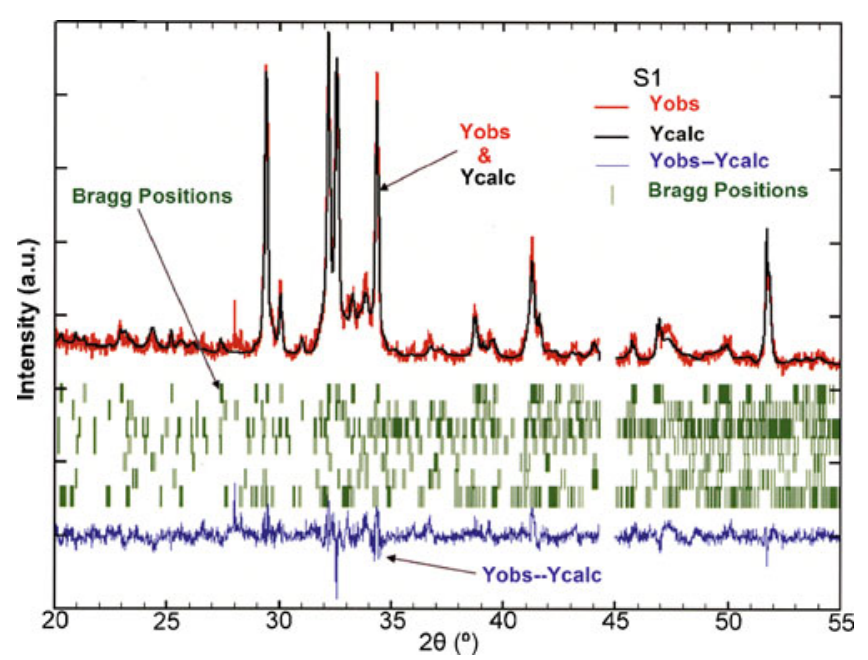

Figure 9. Rietveld refinement of OPC cement sample $S 1$.

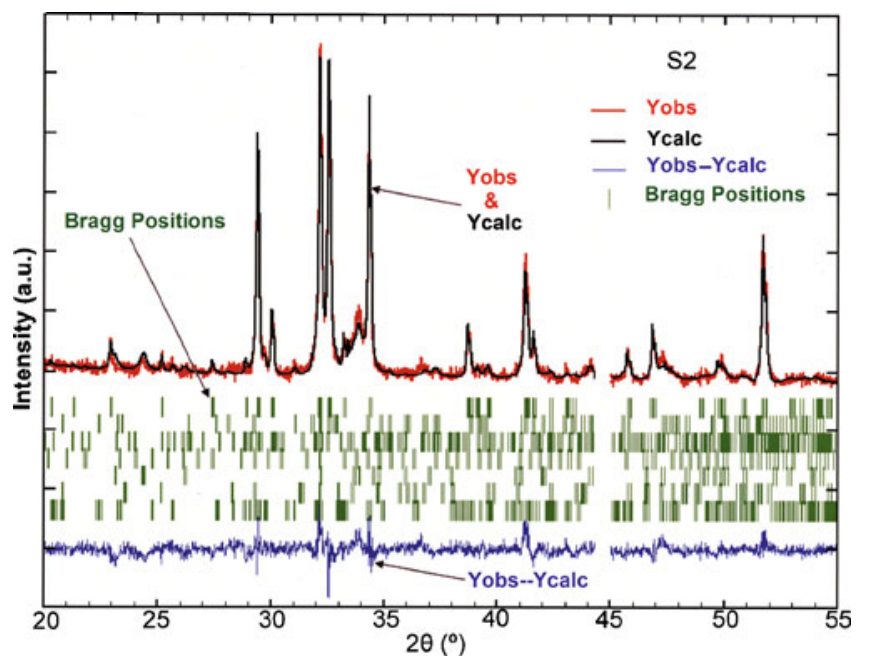

Figure 10. Rietveld refinement of OPC cement sample $S 2$. 
The percentage of $\mathrm{C}_{3} \mathrm{~S}$ component is lowest in sample $S 3$ (48.72\%), highest in sample $S 2(63 \cdot 14 \%)$ and intermediate in sample $S 1$ (54.64\%). This difference in $\mathrm{C}_{3} \mathrm{~S}$ percentage is quite significant and is likely to affect the hydraulic properties of each sample during hydration process. On the other hand, $\mathrm{C}_{2} \mathrm{~S}$ content is the highest in sample $S 3(24.43 \%)$, lowest in sample $S 2(13 \cdot 16 \%)$ and intermediate in sample $S 1(19.70 \%)$. Although there is substantial variation in the relative proportion of $\mathrm{C}_{3} \mathrm{~S}$ and $\mathrm{C}_{2} \mathrm{~S}$ in different samples, the sum of $\mathrm{C}_{3} \mathrm{~S}$ and $\mathrm{C}_{2} \mathrm{~S}$ percentage comes quite close to each other $(72-76 \%), \mathrm{C}_{3} \mathrm{~A}$ contents of samples $S 1$ and $S 2$ are approximately same, $7.40 \%$ and $7.11 \%$, respectively but lower in $S 3$ which is $6.23 \%$. Percentage of $\mathrm{C}_{4} \mathrm{AF}$ is quite

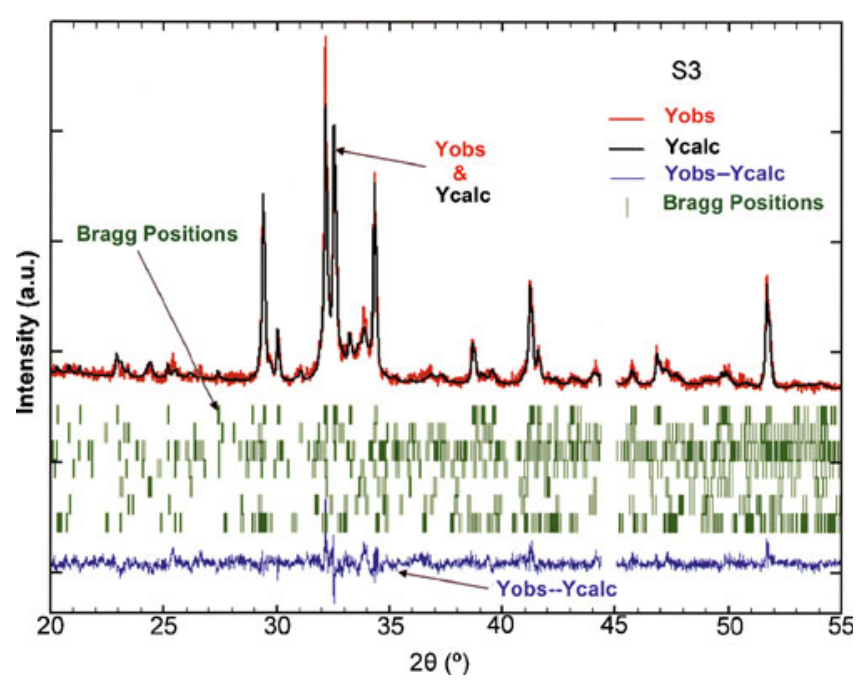

Figure 11. Rietveld refinement of OPC cement sample $S 3$. similar in samples $S 1$ and $S 2,12.17 \%$ and $12.51 \%$, respectively but slightly higher in sample $S 3,14 \cdot 24 \%$. Bogue calculation did not account for $4-6 \%$ of material present in the samples. This difference may be attributed to $4-5 \%$ of gypsum, hemihydrate and other minor phases present in cement samples.

5.3b Rietveld refinement method: In the second stage of quantitative phase analysis of the samples, Rietveld refinement method has been used for more accurate calculations of the phase composition of OPC cement. The calculated diffractogram (black), observed diffractogram (red), difference pattern (blue) and Bragg's positions (green) of the cement samples are shown in figures 9, 10 and 11 for the samples $S 1, S 2$ and $S 3$, respectively.

The phase composition of the cement samples obtained at the end of refinement process and the least square $R$-factors like $R_{\mathrm{p}}, R_{\mathrm{wp}}, R_{\text {exp }}$ and $\chi^{2}$ are shown in table 4 . The $R_{\mathrm{p}}$, $R_{\mathrm{wp}}$ and $R_{\exp }$ values of the samples are in the range of $8-9$, $11-12$ and $8-9$, respectively. The $\chi^{2}$ values obtained for samples $S 1, S 2$ and $S 3$ are $1.81,1.93$ and 1.83 , respectively. For complex materials like cement, these values indicate quite a good fitting of the diffractograms as confirmed by literature data (Taylor and Hinezak 2004).

The alite content of the samples $S 1(58 \cdot 31 \%)$ and $S 2$ $(59.97 \%)$ is quite close to each other, but the alite content of the sample $S 3$ is much lower, which is only $50 \cdot 12 \%$. Similarly the belite content is essentially same in $S 1$ and $S 2$ viz. $19.65 \%$ and $19.29 \%$, respectively but is slightly higher for $S 3$ sample $(21.41 \%)$. This indicates a marked improvement of mass percentage of alite and belite phases present in these samples compared with the values obtained by Bogue method as discussed in previous section. Both cubic

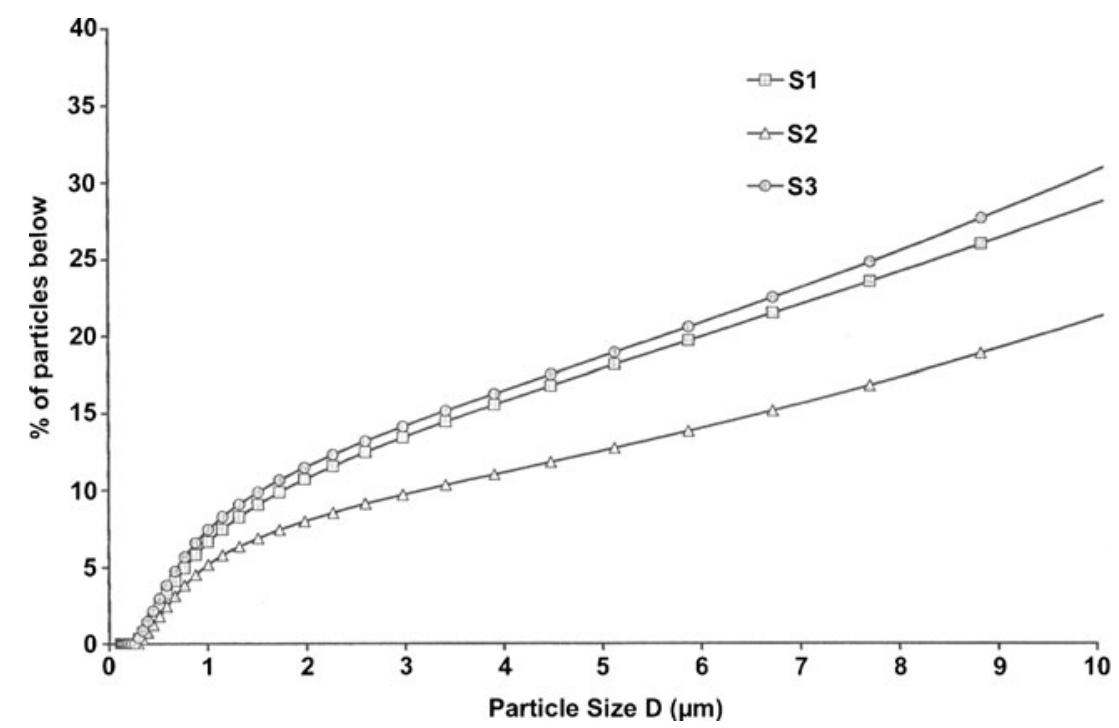

Figure 12. Cumulative particle size distribution $(0-10 \mu \mathrm{m})$ of OPC cement samples $S 1, S 2$ and $S 3$. 
and orthorhombic phases of tricalcium aluminate $\left(\mathrm{C}_{3} \mathrm{~A}\right)$ are present in $S 1$ and $S 3$ samples. In contrast, $\mathrm{C}_{3} \mathrm{~A}$ content of $S 2$ sample is dominated by cubic phase (cubic $9.31 \%$ with orthorhombic only $0.76 \%$ ). The total $\mathrm{C}_{3} \mathrm{~A}$ content of $S 3$ is much higher, $17.27 \%$, in contrast with the other two samples, $S 1$ and $S 2$ where $\mathrm{C}_{3} \mathrm{~A}$ content is in the range of $8-9 \%$. The $\mathrm{C}_{4} \mathrm{AF}$ content of $S 1(8.64 \%)$ and $S 2(8.71 \%)$ is essentially same whereas it is slightly lower in $S 3(6.31 \%)$. The minor phase of calcium sulphate hemihydrate is present in all the samples with their content as $4.48 \%, 1.97 \%$ and $3.62 \%$ in samples $S 1, S 2$ and $S 3$, respectively. Gypsum is present only in $S 1$ and $S 3(1.17 \%$ and $1.27 \%$, respectively) and is highly preferred oriented along 001 direction. The effect of the difference in phase composition of these samples on their hydration performance is explored by quantitative measurement of the degree of hydration of these samples as a function of time in a cement paste with w/c ratio 0.5 and is discussed in the following section. The cumulative particle size distribution data of the three samples up to $10 \mu \mathrm{m}$ size is shown in figure 12 .

\subsection{Quantitative analysis of cement hydration process}

The degree of hydration of these OPC samples was determined as a function of time, by monitoring the change in the relative intensity of $\mathrm{C}_{3} \mathrm{~S}$ peak (at $2 \theta=29.42^{\circ}$ ) with respect to rutile peak (at $2 \theta=27.45^{\circ}$ ) that was used as an internal standard with the reaction products in this work. Figure 13 shows the XRD diffractograms of hydration products of sample $S 1$ as a function of time up to $72 \mathrm{~h}$. The progressive decrease in the intensity of alite peak at $29.42^{\circ}$ with reaction time is quite evident from this set of diffractograms. The relative intensity of this peak with respect to unreacted sample $(0 \mathrm{~h})$ was used to measure the degree of hydration $(\alpha)$.

Figure 14a shows the variation of the degree of hydration $(\alpha)$ as a function of time up to $72 \mathrm{~h}$ for three OPC cement samples $S 1, S 2$ and $S 3$, respectively. It is quite obvious from the results that the induction period of hydration reaction for samples $S 1$ and $S 2$, which have similar level of $\mathrm{C}_{3} \mathrm{~S}$ content, was roughly between 3 and $4 \mathrm{~h}$ and the corresponding period for sample $S 3$, which has about $20 \%$ less $\mathrm{C}_{3} \mathrm{~S}$, is about $6 \mathrm{~h}$. The acceleratory period continues up to $24 \mathrm{~h}$ for all the samples but there is substantial difference in values of degree of hydration $(\alpha)$ in the period 6-24 h. For example, the values of $\alpha$ after $12 \mathrm{~h}$ of hydration are $22 \%$ for $S 1,15 \%$ for $S 2$ and $8 \%$ for $S 3$, respectively. The lower values of $\alpha$ for the sample $S 3$ may be attributed primarily to the higher value of ( $\beta$ $\mathrm{C}_{2} \mathrm{~S} / \mathrm{C}_{3} \mathrm{~S}$ ) ratio which is 0.43 for sample $S 3$ compared with 0.34 and 0.32 for samples, $S 1$ and $S 2$, respectively. It is well known from literature that the higher value of belite to alite ratio in cement clinker reduces the rate of reaction in early stage of cement hydration (Osbeck and Jons 1980). At $24 \mathrm{~h}$, $\alpha$ values of $S 2$ and $S 3$ come closer to each other. The profile of the hydration curves of the samples beyond $24 \mathrm{~h}$, however, show some change in the rate of hydration for samples $S 2$

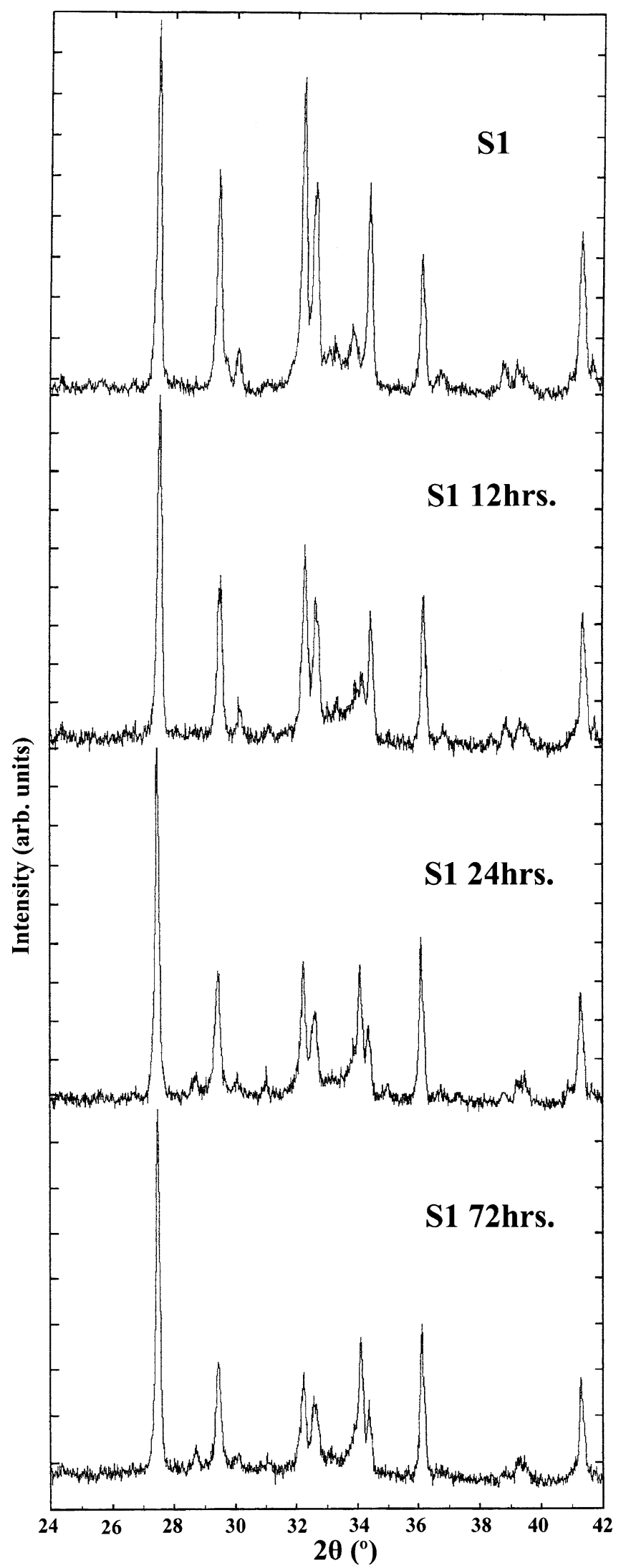

Figure 13. Experimental X-ray diffractograms of hydration products of OPC cement sample $S 1$ along with rutile as a function of time. 
and $S 3$ while $S 1$ increases monotonically. The switch-over of the hydration curves of $S 2$ and $S 3$ beyond 24 h of hydration may be explained from the particle size distribution of these samples.

Since the finer fraction of the particles contributes significantly towards hydration at early stage, we concentrate on the particle size distribution curves of the samples below $5 \mu \mathrm{m}$ (figure 13). A comparison of particle size distribution curves below $5 \mu \mathrm{m}$ show that the cumulative values at $5 \mu \mathrm{m}$ size are quite close for samples $S 1(17.9 \%)$ and $S 3(18.7 \%)$ but is significantly lower for sample $S 2(12.56 \%)$ and that might be one of the reasons for the higher rate of hydration for sample $S 3$ beyond 24 h as compared to sample $S 2$. Further, comparing the performance of samples $S 1$ and $S 2$, the higher degree of hydration of sample $S 1$ may be attributed to higher percentage of finer particles present in sample $S 1$ compared with sample $S 2$, which is otherwise very similar to $S 1$ in terms of phase composition ratio $\beta-\mathrm{C}_{2} \mathrm{~S} / \mathrm{C}_{3} \mathrm{~S}$. Although finer fraction of particle size distribution of $S 3$ below $5 \mu \mathrm{m}$ is slightly better compared with $S 1$, the lower value of $\beta-\mathrm{C}_{2} \mathrm{~S} / \mathrm{C}_{3} \mathrm{~S}$ ratio of $S 1$ is responsible for higher values of degree of hydration of $S 1$ beyond $24 \mathrm{~h}$.

In order to analyse and interpret the comparative hydration performance of these cement samples, we have also computed the theoretical degree of hydration $(\alpha)$ of monodispersed spherical $\mathrm{C}_{3} \mathrm{~S}$ particles as a function of time for
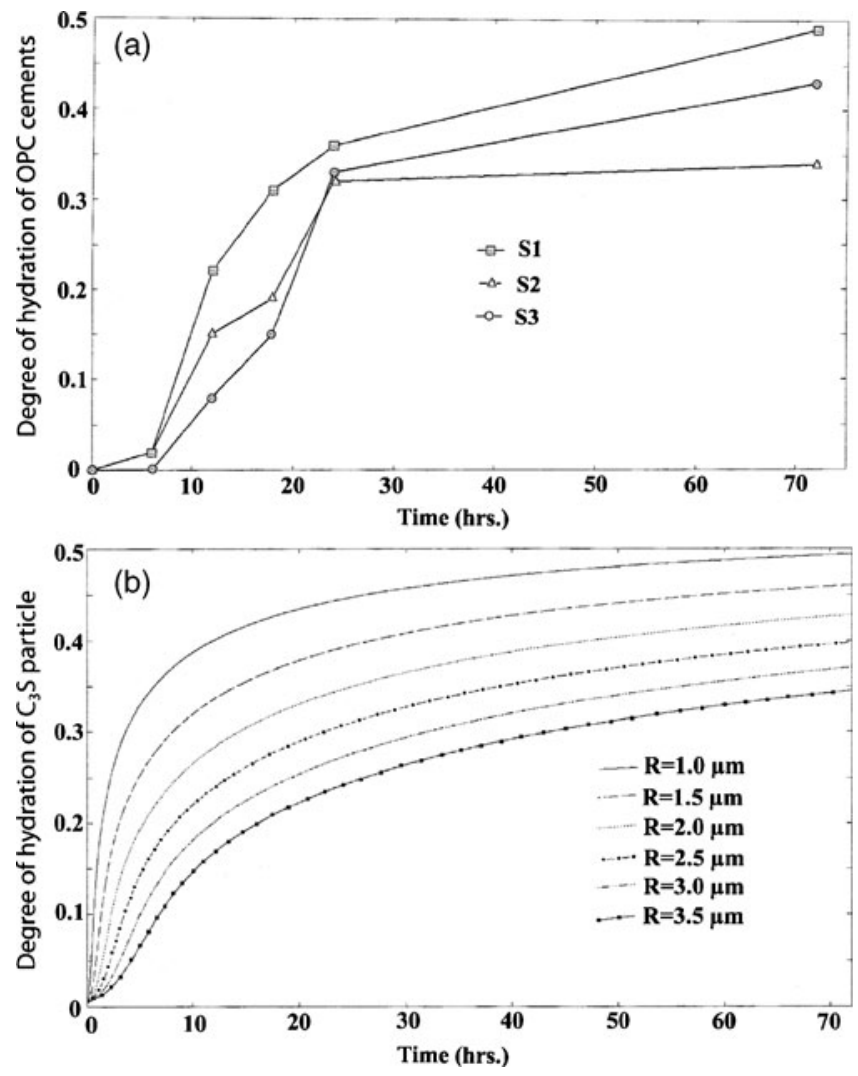

Figure 14. Comparison of experimental (a) and theoretical (b) degree of hydration. water/ $\mathrm{C}_{3} \mathrm{~S}$ ratio of 0.5 and particle sizes varying in the range of 2 to $7 \mu \mathrm{m}$ based on Pommersheim-Clifton model (Pommersheim and Clifton 1979, 1982). The degree of hydration $(\alpha)$ of $\mathrm{C}_{3} \mathrm{~S}$ particles was determined from the numerical solution of (5) and (6). For numerical solution of (5), identical set of base case parameters were used in this work as was originally used by Pommersheim and Clifton (1982) in their work. The computed results of $\alpha$ as a function of time for different particle sizes are shown in figure $14 \mathrm{~b}$. The good similarity of two sets of curves is quite evident from the comparison of figures $14 \mathrm{a}$ and $\mathrm{b}$. This similarly also indicates that the set of experimental curves of degree of cement hydration are well spanned by the set of theoretical curves of $\mathrm{C}_{3} \mathrm{~S}$ hydration when the particle size varies in the range of 2-7 $\mu \mathrm{m}$ leading to the conclusion that the early stage of cement hydration is primarily dominated by finer fraction of cement particles in the range of 2-7 $\mu \mathrm{m}$. More elaborate theoretical analysis of the experimental results of OPC cement hydration process, which also includes the effect of particle size distribution of the samples, will be reported shortly.

\section{Conclusions}

(I) Theoretical X-ray diffractograms are very important for establishing the identity of each component of cement and its crystal phase and also its relative abundance in cement and clinker. Both qualitative and quantitative analyses are very important for a comprehensive characterization of cement and determination of phase composition of cement and clinker.

(II) Calculations of the phase composition of the OPC cement samples based on Rietveld refinement method shows more comprehensive and accurate results compared to Bogue method. All the phases present in a cement sample including the minor phases can be determined by Rietveld refinement method, whereas Bogue method provides data of cement composition based only on four major phases.

(III) The phase composition analysis of three OPC cement samples shows that samples $S 1$ and $S 2$ are quite similar to each other w. r. t. $\beta-\mathrm{C}_{2} \mathrm{~S} / \mathrm{C}_{3} \mathrm{~S}$ ratio $(0.34$ and $0 \cdot 32$, respectively), but the sample $S 3$ is quite different from $S 1$ and $S 2$ with a much higher value of $\beta-\mathrm{C}_{2} \mathrm{~S} / \mathrm{C}_{3} \mathrm{~S}$ ratio $(0.43)$. As a result of this difference in composition, the performance of sample $S 3$ during the early stage hydration reaction is inferior compared to $S 1$ and $S 2$. The finer fraction of cement particles present in the samples influences significantly the degree of hydration at the early stage.

(IV) Comparison of the experimental results of the degree of hydration of OPC cement samples with theoretical degree of hydration of spherical $\mathrm{C}_{3} \mathrm{~S}$ particles with same water/solid ratio $(0.5)$ indicates that the early stage hydration of the samples is dominated significantly by the cement particles in the range of 2-7 $\mu \mathrm{m}$ size. 


\section{Acknowledgements}

We gratefully acknowledge the financial support provided by Ambuja Cement Ltd. for this research project and the analytical support we have received from SAIF, IIT Bombay, in this work. We also thank Prof. J B Joshi, Ex-Director, Institute of Chemical Technology, Mumbai, for suggesting the field of cement research to us and for providing active support and encouragement during the course of this work.

\section{References}

Benzou C, Nonat A J and Mutin C 1995 J. Solid State Chem. 117 165

Bish D L and Howard S A 1988 J. Appl. Crystallogr. 2186

Bogue R H 1955 The chemistry of Portland cement (New York: Reinhold Publication) 2nd ed.

Colville A A and Geller S 1971 Acta Crystallogr. B27 2311

Costa U and Marchi M 2003 Proceedings of 11th ICCC (Durban) p. 151

Cullity B D 1978 Elements of X-ray diffraction (USA: AddisonWesley) 2nd ed.

De La Torre A G, Cabeza A, Calvente A, Bruque S and Aranda M A G 2001 Anal. Chem. 73151

De La Torre A G, Bruque S, Campo J and Aranda M A G 2002 Cem. Concr. Res. 321347

Ferraris C F, Hackley V A and Aviles A I 2004 Cem. Concr. Aggr. 261

Golovastikov N I, Matveeva R G and Belov N V 1975 Sov. Phys. Crystallogr. 20441

Hewlett P C (ed.) 1988 Lea's chemistry of cement and concrete (Oxford: Elsevier Butterworth-Heinemann) 4th ed.

Hill R J and Howard C J 1987 J. Appl. Crystallogr. 20467
Inorganic Crystal Structure Database: http://www.icsd.iqfr.csic.es/ index.html

Jost K H, Ziemer B and Seydel R 1977 Acta Crystallogr. B33 1696

Mondal P and Jeffery J W 1975 Acta Crystallogr. B31 689

Mumme W G 1995 Neues. Jahrb. Mineral. Monatsh 145

Nishi F and Takeuchi Y 1975 Acta Crystallogr. B31 1169

Nishi F and Takeuchi Y 1984 Z. Kristallogr. 168197

Okada K and Ossaka J 1980 Acta Crystallogr. B36 919

Osbeck B and Jons E S 1980 Proceedings of 7th ICCC II II135

Peterson V K 2003 Diffraction investigation of cement clinker and tricalcium silicate using Rietveld analysis, $\mathrm{PhD}$ thesis, University of Technology, Sydney, Australia

Pommersheim J M and Clifton J R 1979 Cem. Concr. Res. 9765

Pommersheim J M and Clifton J R 1982 Cem. Concr. Res. 12 765

Rodríguez-Carvajal J. Fullprof 2000 (version 4.30 Apr. 2008): http://www.ill.eu/sites/fullprof/

Rietveld H M 1969 J. Appl. Crystallogr. 265

Schofield P F, Knight K S and Stretton I C 1996 Am. Mineral. 81 847

Scrivener K L, Füllmann, T, Gallucci E, Walenta G and Bermejo E 2004 Cem. Concr. Res. 341541

Stutzman P E 1996 Guide for X-ray powder diffraction analysis of Portland cement and clinker, NISTIR 5755

Taylor H F W 1997 Cement chemistry (London: Thomas Telford) 2nd ed.

Taylor J C and Hinezak I 2004 Rietveld made easy (Canberra, Australia: Sietronics)

Udagawa S, Urabe K, Natsume M and Yano T 1980 Cem. Concr. Res. 10139

Young R A (ed.) 1993 The Rietveld method, IUCr monographs on crystallography-5 (New York: Oxford Science)

Young R A, Mackie P E and Von Dreele R B 1977 J. Appl. Crystallogr. 10262 